\title{
List of contributing authors
}

(in order of appearance in the book)

Awais Ikram, Faculty of Mechanical Engineering, University of Ljubljana, Ljubljana, Slovenia

Franci Pušavec, Faculty of Mechanical Engineering, University of Ljubljana, Ljubljana, Slovenia

Jürgen Neises, FUJITSU Technology Solutions GmbH, Düsseldorf, Germany

Spyridon Evangelatos, INTRASOFT International S.A., Athens, Greece

Thomas Walloschke, Secon Trust Consult, Berlin, Germany

George Moldovan, Raiffeisen Bank International AG, Vienna, Austria

Hendrik Eikerling, FRAUNHOFER IEM, Paderborn, Germany

Bianca Popovici, Siemens SRL, Brasov, Romania

Cosmin Grigoras, Siemens SRL, Brasov, Romania

Daniel Calvo, ATOS Spain S.A., Santander, Spain

Adrien Hemmer, Institut National de Recherche en Informatique et en Automatique, Nancy, France

John Soldatos, INTRASOFT International S.A., Athens, Greece

Zoran Miljković, Department of Production Engineering, Faculty of Mechanical Engineering, University of Belgrade, Belgrade, Serbia

Lazar Đokić, Department of Production Engineering, Faculty of Mechanical Engineering, University of Belgrade, Belgrade, Serbia

Milica Petrović, Department of Production Engineering, Faculty of Mechanical Engineering, University of Belgrade, Belgrade, Serbia

Bojan Babić, Department of Production Engineering, Faculty of Mechanical Engineering, University of Belgrade, Belgrade, Serbia

Maznah Iliyas Ahmad, Faculty of Mechanical and Manufacturing Engineering, Universiti Tun Hussein Onn Malaysia, Batu Pahat, Johor, Malaysia; Department of Mechanical Engineering, Politeknik Sultan Azlan Shah, Behrang, Perak, Malaysia

Yusri Yusof, Faculty of Mechanical and Manufacturing Engineering, Universiti Tun Hussein Onn Malaysia, Batu Pahat, Johor, Malaysia

Md Elias Daud, Department of Mechanical Engineering, Politeknik Sultan Salahuddin Abdul Aziz Shah, Shah Alam, Selangor, Malaysia

Kamran Latif, Faculty of Mechanical and Manufacturing Engineering Technology, Universiti Teknikal Malaysia Melaka, Durian Tunggal, Melaka, Malaysia 
Aini Zuhra Abdul Kadir, School of Mechanical Engineering, Faculty of Engineering, Universiti Teknologi Malaysia, Skudai, Johor Bahru, Malaysia

Anbia Adam, Faculty of Mechanical and Manufacturing Engineering, Universiti Tun Hussein Onn Malaysia, Batu Pahat, Johor, Malaysia

Noor Hatem, Faculty of Mechanical and Manufacturing Engineering, Universiti Tun Hussein Onn Malaysia, Batu Pahat, Johor, Malaysia

Yazid Saif, Faculty of Mechanical and Manufacturing Engineering, Universiti Tun Hussein Onn Malaysia, Batu Pahat, Johor, Malaysia

Danish Memon, Faculty of Mechanical and Manufacturing Engineering, Universiti Tun Hussein Onn Malaysia, Batu Pahat, Johor, Malaysia

Zohib Khan, Faculty of Mechanical and Manufacturing Engineering, Universiti Tun Hussein Onn Malaysia, Batu Pahat, Johor, Malaysia

Branislav Sredanović, Faculty of Mechanical Engineering, University of Banjaluka, Banja Luka, Bosnia and Herzegovina

Đorđe Čiča, Faculty of Mechanical Engineering, University of Banjaluka, Banja Luka, Bosnia and Herzegovina

Davorin Kramar, Faculty of Mechanical Engineering, University of Ljubljana, Ljubljana, Slovenia Jagadish, Department of Mechanical Engineering, National Institute of Technology, Raipur, India Manjunath Patel G C, Department of Mechanical Engineering, P.E.S. Institute of Technology and Management, Shivamogga, Karnataka, India 